\title{
ANALISIS DISRIMINAN DAN KLASIFIKASI KETEPATAN MASA STUDI MAHASISWA PENDIDIKAN FISIKA
}

\author{
Duden Saepuzaman $^{1}$, Heri Retnawati ${ }^{2}$ \\ 1) Departemen Pendidikan Fisika, FPMIPA, Universitas Pendidikan Indonesia, dsaepuzaman@upi.edu \\ 2) Sekolah Pascasarjana, Program Studi Penelitian dan Evaluasi Pendidikan, Universitas Negeri Yogyakarta.
} Abstrak

\begin{abstract}
Kelulusan tepat waktu mahasiswa merupakan bagian dari penilaian kualitas sebuah perguruan tinggi. Studi ini difokuskan pada analisis diskriminan dan klasifikasi ketepatan masa studi mahasiswa Pendidikan Fisika di FPMIPA UPI. Jumlah responden sebanyak 120 mahasiswa angkatan masuk 2011-2015 dengan komposisi 64 lulusan tepat waktu dan 56 lulusan tidak tepat waktu. Instrumen yang digunakan berupa kuiosoner yang disebar melalui google form. Hasil analisis diskriminan menunjukkan bahwa faktor-faktor yang membedakan ketepatan masa studi meliputi, skor Fisika Dasar 1 ( $\left.x_{1}\right)$, semester saat mahasiswa kontrak skripsi $\left(x_{2}\right)$, frekuensi Bimbingan Akademik per semester $\left(x_{3}\right)$ dan lama/waktu penyusunan skripsi $\left(x_{4}\right)$. Hasil lainnya menunjukkan bahwa model /fungsi diskriminan yang dihasilkan memiliki ketepatan yang sangat tinggi yaitu 95,83\%. Hasil ini diharapkan dapat membantu meningkatkan jumlah lulusan tepat waktu dan mengantisipasi persoalanpersoalan yang berpotensi menghambat penyelesaian studi mahasiswa.
\end{abstract}

Kata kunci : Analisis Diskriminan, klasifikasi, masa studi, Pendidikan Fisika

\begin{abstract}
The timely graduation of students is part of the quality assessment of a university. This study focuses on discriminant analysis and classification of the accuracy of the study period for Physics Education students at FPMIPA UPI. The number of respondents was 120 students entering the 2011-2015 class with a composition of 64 graduates on time and 56 graduates not on time. The instrument used is in the form of a questionnaire distributed via a google form. The results of the discriminant analysis show that the factors that distinguish the accuracy of the study period include the score of Basic Physics 1 ( $\left.x_{1}\right)$,), the semester when students contract thesis $\left(x_{2}\right)$, the frequency of Academic Guidance per semester $\left(x_{3}\right)$ and the length/time of thesis preparation $\left(x_{4}\right)$. Other results show that the resulting discriminant function/model has a very high accuracy of $95.83 \%$. These results are expected to help increase the number of graduates on time and anticipate problems that can hinder the completion of student studies.
\end{abstract}

Keywords: Discriminant Analysis, classification, study period, Physics Education

\section{Pendahuluan}

Seiring berkembangnya ilmu pengetahuan dan teknologi yang semakin pesat diperlukan adanya sumber daya manusia yang berkualitas dan memiliki berbagai kompetensi. Upaya untuk menciptakan Sumber Daya Manusia (SDM) yang unggul dan kompeten harus dimulai dari sejak dini dan dalam prosesnya memerlukan pendidikan baik pendidikan formal, pendidikan informal dan pendidikan non formal. Pendidikan memegang peranan penting dalam menghasilkan SDM yang unggul dan kompeten, tak terkecuali pendidikan tinggi. Secara formal pendidikan tinggi di selenggarakan di perguruan tinggi (UU No 12/2012, 2012). Di perguruan tinggi, data mahasiswa dan ketepatan studi mahasiswa menghasilkan informasi yang penting. Hal ini karena salah satu indikator kinerja Perguruan Tinggi adalah presentasi kelulusan mahasiswa tepat waktu. Hal ini mengacu pada Peraturan Badan Akreditasi Nasional Perguruan Tinggi Nomor 3 tahun 2019 tentang Instrumen Akreditasi Perguruan Tinggi.

Untuk program sarjana atau strata satu (S1), rata-rata waktu yang ditempuh untuk menyelesaikan studi adalah 4 tahun atau 8 semester. Faktor pendukung mahasiswa lulus tepat waktu terdiri dari faktor akademik dan nonakademik. Faktor Akademik meliputi kurikulum, dosen, mahasiswa, layanan akademik, dan sarana-pra sarana. Sedangkan faktor non-akademik meliputi faktor keluarga, lingkungan kampus, lingkungan tempat tinggal dan faktor sosial budaya (Ninla, 2019). Dalam 
prakteknya, banyak juga mahasiswa tingkat akhir yang memiliki masalah keterlambatan waktu kelulusan. Faktor-faktor yang menghambat ketepatan masa studi meliputi kesehatan, intelegensi, kesiapan, bakat, minat, hubungan orangtua dan anak, hubungan antar anggota keluarga, keadaan ekonomi keluarga, latar belakang budaya, hubungan antara dosen dengan mahasiswa, hubungan antara mahasiswa dengan mahasiswa yang lain, kurikulum, disiplin kampus, lingkungan tetangga, aktivitas dalam masyarakat, dan organisasi (Ihsan \& Zaki, 2015). Hal ini sejalan dengan data melalui kuesioner, diperoleh beberapa faktor yang menyebabkan keterlambatan lulus atau lamanya masa studi diperoleh beberapa faktor, seperti IPK mata kuliah, masalah finansial, atau masalah-masalah lain baik yang datangnya dari dalam diri (seperti motivasi, minat dan bakat, pemahaman peluang kerja) maupun dari luar (seperti lingkungan belajar, motivasi dan dorongan orang tua atau orang terdekat). Sebagai contoh di Departemen Pendidikan Fisika FPMIPA UPI untuk lulusan tahun 2019 masa studi mahasiswa berkisar di 4,3 tahun (lebih dari 8 semester). Tentu saja masa studi ini masih dipandang sebagai kelulusan yang tidak tepat waktu. Hal ini merujuk pada struktur kurikulum dan pedoman penyelenggaran Pendidikan di UPI (UPI, 2019) yang diterapkan bahwa untuk S1 dirancang untuk 8 semester dengan masa studi 814 semester, sehingga untuk lulusan yang masa studinya di atas 8 semester dipandang tidak tepat waktu. Untuk meningkatkan kualitas lulusan (mengurangi masa studi yang lebih dari delapan semester) diperlukan upaya dari awal sehingga dapat diberikan treatmen yang tepat agar mereka lulus tepat waktu. Untuk upaya ini, diperlukan pemetaan mengenai karakteristik mahasiswa yang diprediksi menempuh masa studi $\leq 4$ tahun (tepat waktu) atau $>4$ tahun (tidak tepat waktu). Pengklasifikasian menjadi alternatif cara untuk melihat karakteristik mahasiswa yang digolongkan lulus tepat waktu dan lulus tidak tepat waktu agar dapat menjadi gambaran untuk pihak program studi, departemen, fakultas, maupun universitas.

Salah satu metode yang sering dipakai untuk masalah pengklasifikasian adalah analisis diskriminan dan klasifikasi. Diskriminasi dan klasifikasi merupakan teknik multivariat yang berkaitan dengan teknik memisahkan sekumpulan objek yang berbeda (atau pengamatan) dan dengan mengalokasikan objek baru (pengamatan) kedalam kelompok yang sebelumnya didefinisikan (Johnson et al., 2002). Secara umum, diskriminasi dan klasifikasi memiliki dua tujuan utama. Pertama, untuk menggambarkan, baik secara grafis (dalam tiga dimensi atau kurang) atau secara aljabar, fitur diferensial dari objek (pengamatan) dari beberapa koleksi yang diketahui (populasi). Dalam hal ini, mencoba untuk menemukan "diskriminan" yang memiliki nilai numeriknya sedemikian sehingga koleksi dipisahkan sebanyak mungkin (separation).Kedua, Untuk mengurutkan objek (pengamatan) menjadi dua atau lebih kelas yang berlabel (kategori/nominal). Penekanannya adalah pada menurunkan aturan yang dapat digunakan untuk secara optimal menetapkan objek baru ke kelas berlabel (classification or allocation) (Johnson et al., 2002).

Analisis diskriminan ini telah banyak dilakukan di berbagai bidang dengan berbagai tujuan. Dalam bidang ekonomi, analisis diskriminan bisa digunakan untuk membedakan potensi kebangkrutan perusahaan Textile \& Garment yang terdaftar di Bursa Efek Indonesia (BEI) tahun 2016-2018 (Ismanto \& Ernawati, 2021). Fungsi diskriminan juga digunakan untuk mengelompokkan kabupaten/kota masuk ke dalam kategori status indikator IPM rendah, sedang, tinggi, dan sangat tinggi (Nurhasanah et al., 2021). 
Dalam dunia pendidikan dan psikologi, analisis diskriminan digunakan untuk mengetahui faktor-faktor yang mempengaruhi mahasiswa dalam pemilihan Prodi Matematika FMIPA dan FKIP Universitas Sriwijaya (Andriani et al., 2011). Faktor-faktor yang diamati adalah faktor minat, dunia kerja, kapasitas prodi, lingkungan sosial , dan motivasi dunia kerja. Hasil analisis faktor kapasitas prodi dan motivasi dunia kerja yang signikan dapat membedakan pemilihan Prodi Matematika. Penerapan lainnya analisis diskriminan digunakan untuk menyelidiki pengaruh faktor non-kognitif pada sekolah Teknik (Burtner, 2005) . Faktor non-kognitif yang diteliti meliputi harapan dan persepsi profesi teknik, penilaian pribadi, dan kepercayaan pada materi yang dipelajari. Fungsi analisis diskriminan dikembangkan untuk membedakan di antara tiga kelompok yang saling eksklusif; mereka yang tetap tinggal di sekolah teknik, mereka yang tetap di universitas dalam program studi yang berbeda, dan mereka yang meninggalkan universitas sama sekali. Kepercayaan diri yang dilaporkan sendiri dalam kemampuan matematika / sains tingkat perguruan tinggi dan keyakinan bahwa gelar teknik meningkatkan keamanan karir/gaji yang terhormat ditemukan sebagai prediktor yang signifikan pada ketekunan/kegigihan di sekolah Teknik/rekayasa.

Dalam bidang ekonomi, analisis diskriminan digunakan salah satunya dalam memprediksi kebangkrutan atau kesulitan keuangan sebuah perusahaan (Abel Tasman dan Tri Kurniawati, 2014). Melalui analisis prediksi kesulitan keuangan pada perusahaan sektor properti dan real estate, penelitian ini menyimpulkan bahwa ada perbedaan yang signifikan antara kelompok perusahaan Distress dengan kelompok perusahaan Non Distress. Hasil analisis Multivariate Discriminint Analysis merujuk pada kesimpulan bahwa secara signifikan 1 rasio keuangan yang paling berbeda di antara kedua kelompok ini yang dapat pula dikatakan sebagai prediktor kesulitan keuangan perusahaan sektor properti dan real estate di Bursa Efek Indonesia yaitu Rasio Laba Sebelum Bunga dan Pajak terhadap Total Aktiva, hal ini menunjukkan bahwa kemampuan perusahaan dalam menghasilkan laba merupakan syarat yang harus dipenuhi guna menghindarkan dari ancaman kesulitan keuangan dan kebangkrutan.

Analisis Diskriman juga digunakan untuk membuat prediksi kesulitan dan kebangkrutan pada perusahaan-perusahaan yang telah go public di Malaysia (Karbhari \& Muhamad Sori, 2011). Periode penelitian yang digunakan dalam penelitian ini adalah 3 (tiga) tahun dari 1997 sampai tahun 2000. Hasil penelitian ini menunjukkan bahwa rasio-rasio keuangan yang mempengaruhi prediksi kesulitan keuangan adalah Total Liabilities to Total Assets, Asset Turnover, Inventory to Total Assets, Sales to Total Aset dan Cash to Total Assets. Hasil penelitian ini memiliki tingkat ketepatan prediksi sebesar $88 \%$. Hal sejalan juga pernah dilakukan oleh Pane dan Soo (Pane, 2015; Soo et al., 2001).

Secara konseptual, analisis diskriminan digambarkan sebagai perpaduan dari tiga fungsi penting dari analisis statistik (data reduksi, inferensi, dan identifikasi hubungan antar variabel) (Kachigan, 1991). Ini digunakan untuk mengklasifikasikan individu ke dalam kelompok berdasarkan satu atau lebih banyak variabel prediktor atau untuk membedakan kelompok berdasarkan kombinasi linier variabel (Akey et al., 1999). Dalam hal itu, ini mirip dengan regresi berganda, kecuali bahwa variabel kriteria dalam regresi berganda adalah kuantitatif dan variabel kriteria dalam analisis diskriminan adalah kualitatif. Selanjutnya, regresi berganda digunakan agar sesuai dengan sebuah model tunggal untuk serangkaian variabel yang diberikan; sedangkan analisis diskriminan dapat 
menghasilkan beberapa fungsi diskriminan untuk serangkaian variabel prediktor yang diberikan (Field, 2009), atau secara lebih spesfik lagi, analisis diskriminan digunakan pada kasus dimana variabel tak bebas tak bebas berupa data kualitatif (non-metrik) dan variabel bebas berupa data kuantitatif (metrik) (Andriani et al., 2011).

Dalam menerapkan analisis diskriminan, setidaknya ada dua asumsi yang harus dipenuhi. Pertama, matriks kovarian dari semua variabel independent harus sama (kehomogenan matriks kovarian). Kedua, pengujian adanya perbedaan nilai tengah yang siginifikan antara dua kelompok (beda vektor Nilai tengah) (Andriani et al., 2011). Setelah asumsi dipenuhi, analisis dilanjutkan pada penentuan fungsi diskriminan. Salah satu metode yang biasa digunakan adalah analisis diskriminan bertahap (Stepswise Discriminant Analysis).

Dalam dunia Pendidikan, analisis diskriminan juga banyak digunakan. Sebagai contoh, penelitian yang dilakukan Umam (Umam et al., 2015). Studi ini terkait analisis diskriminan melalui metode Fisher terhadap kemampuan siswa dalam menguasai materi bangun ruang pada kelas VIII SMP negeri 1 Banda Aceh tahun pelajaran 2013/2014. Hasil penelitiannya menunjukkan bahwa materi prisma dan limas memang merupakan salah satu materi yang sulit dikuasai siswa kelas VIII SMP Negeri 1 Banda Aceh. Hal ini ditunjukkan oleh hasil perhitungan melalui fungsi diskriminan linier fisher dengan bantuan sofware SPSS (versi 16.0) dimana, siswa yang telah menguasai materi prisma dan limas sebanyak 10 siswa dengan persentase 33,3\% dan siswa yang belum menguasai materi prisma dan limas adalah 20 siswa dengan persentase 66,6 \%. Hal ini menunjukkan bahwa persentase siswa yang belum menguasai materi prisma dan limas lebih banyak dari siswa yang telah menguasai materi prisma dan limas.
Penelitian lain didunia pendidikan adalah penelitian untuk pengelompokan anak (Cahyawati et al., 2011). Tujuan penelitian ini adalah mendapatkan fungsi diskriminan untuk mengelompokkan anak usia $7-15$ tahun, khususnya yang berasal dari keluarga yang terindikasi miskin di Kabupaten Ogan Ilir, kedalam kelompok yang berisiko putus sekolah atau tidak. Hasil analisis menunjukkan sebanyak $14,19 \%$ anak mengalami putus sekolah pendidikan dasar. Fungsi diskriminan yang diperoleh menunjukkan bahwa faktor-faktor yang signifikan menentukan kelompok anak berisiko putus sekolah pendidikan dasar adalah umur kepala rumah tangga, pendidikan ayah, motivasi orangtua dan motivasi anak. Nilai pemisah kelompok anak putus sekolah dan tidak putus sekolah adalah -1,605, artinya, untuk seorang anak yang mempunyai skor fungsi diskriminan lebih kecil atau sama dengan -1,605, anak tersebut termasuk kedalam kelompok yang berisiko putus sekolah sedangkan anak dengan skor fungsi diskriminan lebih besar dari -1,605, anak tersebut termasuk kedalam kelompok yang tidak putus sekolah. Tingkat ketepatan fungsi pengelompokkan ini sebesar 89,86\%.

Studi ini difokuskan pada pemanfaatan analisis diskriminan dalam memprediksi kelulusan tepat waktu atau ketepatan studi mahasiswa di Departemen Pendidikan Fisika FPMIPA UPI. Berdasarkan data studi pendahuluan, diperoleh bahwa beberapa faktor yang mempengaruhi masa studi mahasiswa di departemen Pendidikan Fisika FPMIPA UPI diantaranya, IPK terutama IPK semester II , semester dimana mahasiswa mengontrak skripsi, semester dimana mahasiswa mengontrak PPL, frekuensi bimbingan dengan pembimbing akademik, dan frekuensi bimbingan dengan pembimbing skripsi (Andriani et al., 2011). Data lainnya berdasarkan data yang diperoleh penulis selama mengajar diperoleh bahwa ada hubungan yang linear antara kelulusan tepat waktu dengan 
nilai fisika Dasar I. Sehingga penelitian ini bertujuan menentukan diskriminan dan klasifikasi ketepatan masa studi mahasiswa Pendidikan fisika di FPMIPA UPI pada tahun angkatan masuk 2011-2015 atau yang mulai lulus 2015 sampai sekarang berdasarkan faktorfaktor tersebut. Diharapkan hasil studi ini dapat membantu meningkatkan jumlah lulusan tepat waktu dan mengantisipasi persoalan-persoalan yang berpotensi menghambat penyelesaian studi mahasiswa.

\section{Metode Penelitian}

\section{Pengumpulan Data}

Data yang digunakan adalah data primer menggunakan kuiosner yang disebar kepada alumni departemen Pendidikan Fisika FPMIPA UPI Angkatan masuk 2011 sampai 2015 yang menjadi sampel penelitian. Instrumen/kuisoner yang digunakan berdasarkan tujuan yang meliputi lama studi, IPK semester II, semester berapa mengontrak skripsi, semester berapa mengontrak PPL, frekuensi bimbingan dengan pembimbing akademik, frekuensi bimbingan dengan pembimbing skripsi, serta nilai Fisika Dasar I. Penyebaran kuisoner berbantuan google form dengan url

https://forms.gle/Fr2E7SyMW8WewLPy7.

Berdasarkan metode ini terkumpul sebanyak 120 responden. Dari 120 responden/lulusan terdapat mahasiswa yang lulus tepat waktu sebanyak 64 lulusan, sebanyak 56 lulusan tidak tepat waktu.

\section{Tahapan-tahapan}

Beberapa tahapan yang dilakukan dalam studi ini meliputi kegiatan berikut

1. Menyusun item kuisoner (instrument) dan uji validitas dan reliabilitas sampel kecil

2. Menyebarkan kuisoner kepada responden

3. Deskripsi data tentang response dari alumni terkait faktor-faktir yang mempengaruhi lama studi di Departemen Pendidikan Fisika

4. Pemeriksaan asumsi dasar (a) Uji kehomogenan matriks kovarians gabungan menggunakan uji Box'M dengan membandingkan siginifikannya terhadap taraf nyata $(\alpha)$.

(b) Uji beda vector nilai tengah dengan menggunakan bantuan output SPSS pada tabel Test of equality of Group Means dan membandingkan dengan taraf nyata $(\alpha)$.

5. Penerapan Analisis Diskriminan Linear untuk menentukan fungsi diskriminan.

(a) Menentukan nilai rataan variabel masing-masing kelompok yang dapat dilihat dari output SPSS bagian descriptive.

(b) Menetukan matriks kovarian gabungan dan invers kovarian gabungannya.

(c) Menentukan nilai koefisien fungsi diskriminan

(d) Mensubstitusikan nilai-nilai koefisien fungsi diskriminan yang diperoleh pada langkah (c) ke dalam fungsi diskriminan linear.

6. Melakukan analisis diskriminan bertahap (Stepswise Discriminant Analysis) yang diawali dengan fungsi tanpa variabel (Johnson et al., 2002). Selanjutnya dipilih satu demi satu variabel yang akan dimasukan kedalam fungsi. Fungsi yang terbentuk pada setiap tahap diuji Fhitungnya melalui pendekatan nilai Wilk's Lambda $(\Lambda)$ untuk setiap variabel. Pemilihan variabel berdasarkan nilai Wilk's Lambda $(\Lambda)$ terkecil dengan signifikansi $F$ lebih kecil dari taraf kepercayaan $p>\alpha$, dimana signifikan $F=P\left(F \geq F_{0}\right)=p$. Variabel terpilih diartikan sebagai variabel yang benar-benar berperan dalam membedakan antar kelompok pengamatan. Nilai Wilk's Lambda $(\Lambda)$ diberikan sebagai berikut.

$$
\Lambda=\frac{S S_{w}}{S S_{T}}
$$


dengan $S S_{w}=$ jumlah kuadrat Dalam kelompok ; $S S_{T}=$ jumlah kuadrat total $=$ $S S_{w}+S S_{B}$, dan $S S_{B}=$ jumlah kuadrat Antar kelompok

Setelah fungsi memiliki satu variabel, kemudian dilanjutkan dengan pemilihan variabel dengan dua variabel berdasarkan nilai Wilk's Lambda terkecil dengan $p>\alpha$, dalam artian proses berakhir jika penambahan variabel betikutnya tidak signikan lagi pada sebaran $F$ (Johnson et al., 2002). Selanjutnya, prosedur pemilihan variabel untuk dikeluarkan satu per satu dari fungsi diskriminan, dimulai dari fungsi dengan semua variabel.

Pemilihan variabel untuk dikeluarkan dari fungsi berdasarkan Wilk's Lambda dengan nilai signifikan $F$ lebih besar dari taraf kepercayaan. Proses diberhentikan apabila nilai Wilk's Lambda sudah memenuhi signikan $F$ leih kecil dari taraf kepercayaan.

\begin{tabular}{|c|c|c|c|c|}
\hline & Var. Bebas & $\mathbf{F}$ & Sig. & Perbedaan \\
\hline 1. & $\begin{array}{l}\text { Skor Fisika Dasar } \\
\text { I }\end{array}$ & 353,202 &, 000 & Ada \\
\hline 2. & IPK semester 2 & 75,925 & ,000 & Ada \\
\hline 3. & $\begin{array}{l}\text { Semester Kontrak } \\
\text { Skripsi }\end{array}$ & 39,345 &, 000 & Ada \\
\hline 4. & $\begin{array}{l}\text { Frekuensi } \\
\text { Bimbingan } \\
\text { Akademik }\end{array}$ & 284,544 &, 000 & Ada \\
\hline 5. & $\begin{array}{l}\text { Frekuensi } \\
\text { Bimbingan } \\
\text { Skripsi }\end{array}$ & 135,455 &, 000 & Ada \\
\hline 6. & $\begin{array}{l}\text { Lama } \\
\text { Penyusunan } \\
\text { Skripsi }\end{array}$ & 56,450 &, 000 & Ada \\
\hline
\end{tabular}

Dalam prosedur ini, variabel pertama yang dipilih adalah variabel yang paling penting pertama dalam membedakan masing-masing kelompok dan seterusnya. Jadi variabel diurutkan menurut pentingnya. Variabel yang sudah masuk ke dalam fungsi diskriminan dapat saja dikeluarkan pada tahap-tahap berikutnya. Proses akan berhenti bila tidak ada lagi variabel yang dimasukkan ke dalam fungsi diskriminan dan dikeluarkan dari fungsi diskriminan.
7. Menentukan fungsi diskriminan hanya dengan variabel yang siginfikan memberikan perbedaan

8. Mengevaluasi fungsi diskriminan melalui canonical correlation dan eigen value untuk mengukur keeratan hubungan antara diskriminan skor dan grup.

9. Menentukan ketepatan model/fungsi diskriminan

10. Fungsi diskriminan yang dihasilkan bisa digunakan untuk memprediksi pengelompokkan berdasarkan input pengamatan atau nilai variabel independent tertentu.

\section{Hasil Dan Pembahasan}

\section{Hasil Uji Asumsi Dasar Analisis Diskriminan}

Uji kehomogenan matriks kovarian. Uji ini dilakukan menggunakan uji Box's $\mathrm{M}$ dengan berbantuan SPSS 17.00 dan diperoleh nilai Sig. sebesar 0,142 yang lebih besar dari 0,05 berarti $H_{0}$ diterima yang artinya bahwa matriks kovarian antar kedua kelompok sama.

Uji Beda Antar kelompok. Sebelum dilakukan analisis diskriminan, terlebih dahulu harus dilihat kemungkinan adanya perbedaan variabel antar kelompok. Dengan menggunakan uji F diperoleh data seperti yang disajikan dalam Tabel 1.

Tabel 1. Uji Perbedaan Variabel bebas antar kelompok

Berdasarkan data tabel 1, nampak semua variabel bebas antar kelompok berbeda. Sehingga semua variabel dimasukan dalam penentuan fungsi diskriminasi.

\section{Analisis Diskriminan}

Langkah pertama dalam penentuan Fungsi diskriminasi adalah menetukan variabel mana saja yang layak untuk dimasukkan dalam fungsi diskriminasi. Untuk tujuan ini, dengan berbatuan SPSS 17.00 diperoleh variabel bebas yang dapat 
dimasukan dalam fungsi diskriminasi seperti disajikan dalam tabel 2.

Tabel 2. Variabel yang layak dimasukan dalam Fungsi Diskriminasi

\begin{tabular}{clr}
\hline Tahap & \multicolumn{1}{c}{$\begin{array}{c}\text { Variabel Bebas yang } \\
\text { dimasukan }\end{array}$} & $\begin{array}{c}\text { F hitung } \\
\text { (statistic) }\end{array}$ \\
\hline 1 & $\begin{array}{l}\text { skor Fisika Dasar 1 } \\
\text { semester saat mahasiswa }\end{array}$ & 206,987 \\
& $\begin{array}{l}\text { kontrak skripsi } \\
\text { frekuensi Bimbingan Akademik } \\
\text { per semester }\end{array}$ & 150,818 \\
& $\begin{array}{l}\text { lama/waktu penyusunan skripsi } \\
4\end{array}$ & 128,881 \\
\hline
\end{tabular}

Berdasarkan data tabel 2 diperoleh bahwa dari enam variabel input, hanya ada empat varibel yang layak dimasukkan dalam fungsi diskriminasi. Karena proses yang digunakan adalah analisis diskriminan bertahap (Stepswise Discriminant Analysis), maka pemasukan variabel bebas akan dimulai dengan variabel yang mempunyai angka $\mathrm{F}$ hitung (statistic) terbesar sehingga berturut-turut yaitu skor Fisika Dasar 1, Frekuensi Bimbingan Akademik, Semester kontrak Skripsi, dan lama penyusunan Skripsi. Hasil ini sedikit berbeda dengan penelitian Aprilia, dkk (Aprilia K et al., 2016) yang menyatakan bahwa IPK semeseter 2 sangat menentukan ketepatan masa studi mahasiswa di FMIPA UNPAD. Hal ini sangat dimungkinkan karena terdapat perbedaan karakteristik mahasiswa departemen Pendidikan Fisika FPMIPA UPI dengan FMIPA UNPAD.

Penentuan Fungsi diskriminan dapat disusun dari output Canonical Discriminant Function Coefficient. Berdasarkan output ini dapat disusun koefisien baku fungsi diskriminan seperti yang disajikan dalam tabel 3 .

Tabel 3. Koefisien Fungsi Diskriminan

\begin{tabular}{llr}
\hline \multicolumn{1}{c}{ Variabel Bebas } & \multicolumn{2}{c}{$\begin{array}{c}\text { Koefisien } \\
\text { Fungsi }\end{array}$} \\
\hline 1. & skor Fisika Dasar 1 & 0,103 \\
2. & semester saat mahasiswa & $-0,831$ \\
& kontrak skripsi & \\
3. & frekuensi Bimbingan & 0,237 \\
& Akademik per semester
\end{tabular}

4. lama/waktu penyusunan skripsi

Konstanta

$-0,159$

$-0,667$

Berdasarkan data ini maka dapat dibuat fungsi diskriminan :

$$
\begin{aligned}
D= & 0,103 x_{1}-0,831 x_{2}+0,237 x_{3}-0,159 x_{4}- \\
& 0,667
\end{aligned}
$$

dengan :

$x_{1}=$ skor Fisika Dasar 1

$x_{2}=$ semester saat mahasiswa kontrak skripsi

$x_{3}=$ frekuensi Bimbingan Akademik per semester

$x_{4}=$ lama/waktu penyusunan skripsi

Koefisien fungsi diskriminan yang standar pada varibel $x_{1}$ dan $x_{3}$ bertanda positif, artinya varibel $x_{1}$ dan $x_{3}$ mempunyai pengaruh yang positif, terutama frekuensi bimbingan dengan pembimbing akademik (0,237). Hal ini ditunjukan dengan koefisien fungsi diskriminan yang besar. Dari nilai koefisien yang positif ini, secara umum dapat dikatakan bahwa frekuensi bimbingan akademik dan skor fisika dasar 1 sangat berpengaruh secara linear terhadap tingkat kelulusan tepat waktu mahasiswa. Hal ini bisa dijelaskan bahwa semakin sering bimbingan, peluang munculnya masalah yang menghambat penyelesaian studi bisa diminimalisir atau seandainya terjadi dapat segera dicari alternatif solusi terbaik sehingga tidak menghambat penyelesaian studi mahasiswa. Terkait pemahaman mahasiswa terhadap konsep fisika Dasar tentu saja sangat membantu untuk memahami materi-materi berikutnya dan memahami konsep-konsep fisika sehingga akan membantu dalam perkuliahan mata kuliah yang lain termasuk juga pada saat mereka PPL dan menyusun skripsi. Sebaliknya untuk semester mahasiswa mengontrak skripsi dan lama penyusunan skripsi berpengaruh negatif (berkorelasi negatif) atau memberi kontribusi banyak pada kelulusan mahasiswa yang tidak tepat waktu. Terutama untuk letak semester mahasiswa mengintrak skripsi, memiliki koefisien negatif terbesar $(-0,831)$ 
dibandingkan dengan koefisien fungsi diksriminan yang lainnya.

Fungsi diskriminan yang dihasilkan dalam penelitian secara umum menunjukkan bahwa faktor akademik sangat mendukung terhadap penyelesaian studi tepat waktu. Hal ini sejalan dengan Ninla (2019) yang menunjukkan bahwa faktor sangat mendukung masa studi mahasiswa (Ninla, 2019). Sejalan dengan ini penelitian lain menunjukkan adanya korelasi antara faktor akademik dengan kemampuan mahasiswa menyelesaikan studi (Suwarna, 2010).

\section{Evaluasi Fungsi Diskriminan}

Fungsi Diskriminan memberikan nilai-nilai yang sedekat mungkin dalam kelompok dan sejauh mungkin antar kelompok. Karena terdapat dua kelompok, maka terbentuk suatu fungsi diskriminan yang masing-masing dapat menerangkan persen keragaman seperti disajikan dalam tabel 4.

Tabel 4. Fungsi Diskriminan kanonik

\begin{tabular}{ccccc}
\hline Fungsi & $\begin{array}{c}\text { Nilai } \\
\text { eigen }\end{array}$ & $\begin{array}{c}\text { Keragaman } \\
(\boldsymbol{\%})\end{array}$ & $\begin{array}{c}\text { Kumulatif } \\
(\boldsymbol{\%})\end{array}$ & $\begin{array}{c}\text { Korelasi } \\
\text { Kanonik }\end{array}$ \\
\hline 1 & 4.483 & 100 & 100 & 0,904 \\
\hline
\end{tabular}

Untuk melihat kebaikan dari fungsi diskriminan, dapat dilihat dari nilai korelasi kanonik. Tabel 4 dapat diinterpretasi bahwa pada fungsi diskriminan , $100 \%$ keragaman antara kelompok lulus tepat waktu dengan lulus tidak tepat waktu dapat diserap oleh fungsi dengan korelasi kanonik sebesar 0,904 memaksimumkan keragaman antara kelompok lulus tepat waktu dengan lulus tidak tepat waktu yang belum dijelaskan oleh fungsi diskriminan.

\section{Analisis Klasifikasi}

Seperti telah dijelaskan sebelumnya bahwa selain untuk menemukan fungsi diskriminan yang mampu mengelompokkan objek menjadi dua kelompok, langkah selanjutnya adalah berdasarkan fungsi diskriminan yang terbentuk kita dapat menetapkan objek baru ke kelompok tertentu (classification or allocation). Untuk tahapan ini, kita bisa tentukan rerata untuk masing-masing kelompok. Rerata ini bisa dintentukan dari sentroid masing-masing fungsi kelompok seperti yang disajikan dalam tabel 5 .

Tabel 5. Fungsi sentroid kelompok

\begin{tabular}{lc}
\hline & Fungsi \\
\hline Lulus Tidak Tepat waktu & $-2,245$ \\
Lulus Tepat waktu & 1,964 \\
\hline
\end{tabular}

Secara umum, pemisahan kedua kelompok ini bisa juga dinyatakan dalam bentuk visual seperti yang disajikan dalam gambar 1 .

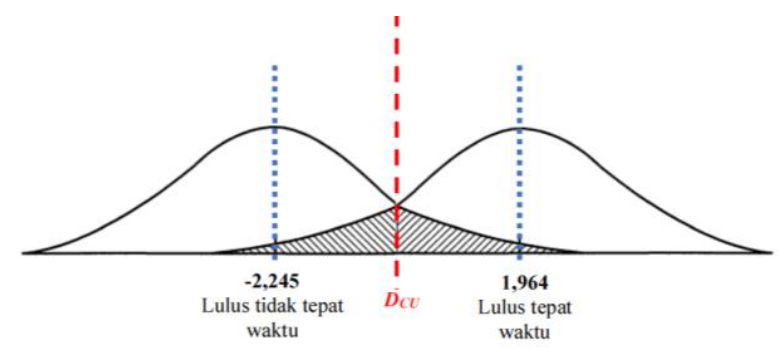

Gambar 1. Skema Kurva dan sentroid kedua kelompok

Selain cara sebelumnya, dari data sentroid kedua kelompok dapat diperoleh fungsi diskriminan dengan menggunakan metode Fisher. Prinsip dasar metode ini adalah memaksimumkan jarak antar sentroid. Fungsi diskriminan diperoleh dari selisih masingmasing fungsi diskriminan atau fungsi $\mathrm{z}$ score kedua kelompok. Hasilnya tidak berbeda jauh dengan hasil sebelumnya.

Analisis klasifikasi bisa ditentukan dengan menetukan nilai kritis (cut off), $D_{C U}$. Nilai $D_{C U}$ ditentukan dengan menggunakan persamaan

$$
D_{C U}=\frac{n_{1} D_{1}+n_{2} D_{2}}{n_{1}+n_{2}}
$$

dalam studi ini diketahui bahwa $n_{1}=56 ; D_{1}=$ $-2,245, n_{2}=64, D_{2}=1,964$, sehingga akan diperoleh nilai $D_{C U}=-0,0002$ atau mendekati nol. Sehingga jika ada objek (pengamatan) baru dengan nilai $x_{1}, x_{2}, x_{3}, x_{4}$ tertentu, maka nilai $D$ yang diperoleh dibandingkan dengan nilai 
$D_{C U}$. Jika $D<D_{C U}$ maka objek tersebut akan dimasukan ke kelompok yang diprediksi tidak akan lulus tepat waktu, begitupun sebaliknya jika $D>D_{C U}$ maka dimasukan ke kelompok yang diprediksi akan lulus tepat waktu.

Meskipun telah diperoleh fungsi diksriminan dan nilai kritis untuk klasifikasi, bukan berarti fungsi ini tepat sepenuhnya dalam mengelompokkan dan memprediksi input yang ada kedalam kelompok tertentu. Ketepatan atau ketidaktepatan fungsi diskriminan (misclassification) dalam mengelompokkan dapat dilihat dari output SPSS pada bagian Classification Result. Secara umum hasil klasifikasi fungsi diskriminan disajikan dalam tabel 6.

Tabel 6. Hasil klasifikasi

\begin{tabular}{ccccc}
\hline & & \multicolumn{2}{c}{ Predicted Group Membership } & \\
\cline { 3 - 4 } Count & $\begin{array}{c}\text { lulus tidak } \\
\text { tepat waktu }\end{array}$ & $\begin{array}{c}\text { lulus Tepat } \\
\text { waktu }\end{array}$ & Total \\
\hline \multirow{2}{*}{$\%$} & $\begin{array}{c}\text { lulus tidak } \\
\text { tepat waktu }\end{array}$ & 54 & 2 & 56 \\
\cline { 2 - 4 } & $\begin{array}{c}\text { lulus Tepat } \\
\text { waktu }\end{array}$ & 3 & 61 & 64 \\
\cline { 2 - 4 } & $\begin{array}{c}\text { lulus tidak } \\
\text { tepat waktu }\end{array}$ & 96,4 & 3,6 & 100,0 \\
\cline { 2 - 4 } & $\begin{array}{c}\text { lulus Tepat } \\
\text { waktu }\end{array}$ & 4,7 & 95,3 & 100,0 \\
\hline
\end{tabular}

Berdasarkan data tabel 6, nampak bahwa mahasiswa yang pada data awal masuk di kelompok lulus tidak tepat waktu sebanyak 56, menurut fungsi diskriminan terdapat 54. Artinya ada 2 mahasiswa yang dikelompokkan keliru (misclassification) . Sedangkan untuk yang data awal lulus tepat waktu sebanyak 64, menurut fungsi diskriminan sebanyak 61 mahasiswa atau 3 mahasiswa yang dikelompokkan keliru (misclassification). Berdasarkan data ini, dapat dibuatkan ketepatan model atau fungsi diskriminan yang dibentuk, sebesar $(54+61) / 120=95,83 \%$. Angka ini bermakna ketepatan model atau fungsi diskriminan yang dihasilkan sangat tinggi. Sehingga model diskriminan ini bisa digunakan untuk memprediksi ketepatan masa studi mahasiswa.

\section{Kesimpulan}

Berdasarkan hasil dan pembahasan dapat disimpulkan bahwa analisis diskriminan dan fungsi diskriminan yang terbentuk diperoleh bahwa faktor-faktor yang membedakan kelulusan tepat waktu/ ketepatan masa studi meliputi, skor Fisika Dasar $1\left(x_{1}\right)$, semester saat mahasiswa kontrak skripsi $\left(x_{2}\right)$, frekuensi Bimbingan Akademik per semester $\left(x_{3}\right)$ dan lama/waktu penyusunan skripsi $\left(x_{4}\right)$ dengan fungsi diksriminan, $D=0,103 x_{1}-0,831 x_{2}+$ $0,237 x_{3}-0,159 x_{4}-0,667$. Faktor yang mempengaruhi secara linear positif terhadap ketepatan masa studi adalah frekuensi Bimbingan Akademik per semester diikuti skor Fisika Dasar 1. Sedangkan faktor yang mempengaruhi secara linear negatif terhadap ketepatan masa studi semester saat mahasiswa kontrak skripsi diikuti lama/waktu penyusunan skripsi. Sedangkan untuk analisis klasifikasi sebagai prediksi menghasilkan nilai kritis di $D_{C U}=-0,0002$. Hasil lainnya menunjukkan bahwa model /fungsi diskriminan yang dihasilkan memiliki ketepatan yang sangat tinggi yaitu 95,83\%. Sehingga layak untuk digunakan dalam memprediksi ketepatan masa studi mahasiswa. Implikasinya hasil ini dapat membantu untuk mengantisipasi permasalahanpermasalahan yang berpotensi memperlama masa studi mahasiswa, mengoptimalkan usahausaha yang bisa dilakukan sehingga meningkat jumlah mahasiswa yang lulus tepat waktu.

\section{Daftar Pustaka}

Abel Tasman dan Tri Kurniawati. (2014).

Prediksi Kesulitan Keuangan dan Kebangkrutan Perusahaan Sektor Properti dan Real Estate dengan Pendekatan Analisis Multivariat Diskriminan. Jurnal Kajian Manajemen Bisnis, 3(01).

Akey, T. M., Salkind, N. J., \& Green, S. B. 
(1999). Using SPSS for Windows: Analyzing and Understanding Data with Disk. Prentice Hall.

Andriani, Y., Cahyani, D., \& Gusmaryanita, V. (2011). Analisis Diskriminan untuk Mengetahui Faktor yang Mempengaruhi Pilihan Program Studi Matematika di FMIPA dan FKIP Universitas Sriwijaya. Jurnal Penelitian Sains, 14(4), 168226.

Aprilia K, T., Gusriani, N., \& Parmikanti, K. (2016). Klasifikasi Ketepatan Masa Studi Mahasiswa FMIPA Unpad Angkatan 2001-2006 dengan Menggunakan Metode Classification and Regression Trees (CART). Jurnal Matematika Integratif, 11(1), 7. https://doi.org/10.24198/jmi.v11i1.7944

Burtner, J. (2005). The use of discriminant analysis to investigate the influence of non-cognitive factors on engineering school persistence. Journal of Engineering Education, 94(3), 335-338.

https://doi.org/10.1002/j.2168-

9830.2005.tb00858.x

Cahyawati, D., Dwipurwani, O., Cahyawati, W. B. S. D., \& Bertran, W. (2011). Aplikasi Analisis Diskriminan Dalam Menentukan Fungsi Pengelompokkan Anak Putus Sekolah Pendidikan Dasar.

Field, A. (2009). Discovering statistics using SPSS. Sage.

Ihsan, H., \& Zaki, A. (2015). Analisis Faktor yang Menghambat Penyelesaian Studi Mahasiswa FMIPA UNM. Scientific Pinisi, 1(1), 25-33.

Ismanto, D., \& Ernawati, D. (2021). Analisis Diskriminan Untuk Memprediksi Kebangkrutan Perusahaan: Studi Kasus Pada Perusahaan Sektor Textile Dan Garment Di Bursa Efek Indonesia 20162018. Jurnal Sains Sosio Humaniora, 5(1), 132-140.

Johnson, R., A, Wichern, D., \& W. (2002). Applied multivariate statistical analysis (Vol. 5, Issue 8)). Prentice hall.
Kachigan, S. K. (1991). Multivariate statistical analysis: A conceptual introduction. In New York Radius Press (Vol. 2nd). Radius Press.

http://www.amazon.com/dp/0942154916

Karbhari, Y., \& Muhamad Sori, Z. (2011). Prediction of Corporate Financial Distress: Evidence from Malaysian Listed Firms during the Asian Financial Crisis. In $S S R N$ Electronic Journal. https://doi.org/10.2139/ssrn.596607

Ninla, E. (2019). Faktor-Faktor Pendukung Mahasiswa Dalam Mengikuti Pendidikan Di Program Studi Pgsd Penjas Fik Uny Kampus WateS. http://staffnew.uny.ac.id/upload/13141108 1/penelitian/20.+IDENTIFIKASI+FAKTO R-

FAKTOR+PENDUKUNG+MAHASISW A+DALAM+MENGIKUTI+PENDIDIKA $\mathrm{N}+\mathrm{DI}+\mathrm{PROGRAM}+\mathrm{STUDI}+\mathrm{PGSD}+\mathrm{PEN}$ $\mathrm{JAS}+\mathrm{FIK}+\mathrm{UNY}+\mathrm{KAMPUS}+\mathrm{YOGYAKA}$ RTA.pdf

Nurhasanah, N., Salwa, N., Ornila, L., AR, F., \& Hasan, A. (2021). Analisis Diskriminan dalam Menentukan Fungsi

Pengelompokan Kabupaten/Kota di Indonesia berdasarkan Indikator Indeks Pembangunan Manusia. Jurnal EMT KITA, 5(1), 37. https://doi.org/10.35870/emt.v5i1.320

Pane, R. (2015). Analisis Diskriminan Untuk Memprediksi Kebangkrutan Perusahaan (Studi pada Perusahaan Manufaktur yang Terdaftar di Bursa Efek Indonesia Tahun 2011-2013). Jurnal Administrasi Bisnis S1 Universitas Brawijaya, 27(2), 86400.

Soo, W., Mat Nor, F., \& Yatim, Y. (2001). Predicting Corporate Financial Distress Using The Logit Model: The Case Of Malaysia. Asian Academy of Management Journal (AAMJ), 6(1), 1-13.

Suwarna, I. P. (2010). Korelasi kemampuan akademik mahasiswa terhadap penyelesaian studi di program studi pendidikan fisika. 
Umam, K., Yuhasriati, Y., \& Nadya, N. (2015). Analisis Diskriminan Melalui Metode Fisher Terhadap Kemampuan Siswa Dalam Menguasai Materi Bangun Ruang Pada Kelas Viii Smp Negeri 1 Banda Aceh Tahun Pelajaran 2013/2014. Jurnal Natural Unsyiah, 15(1), 116209. https://doi.org/10.24815/jn.v15i1.4347

UPI. (2019). Pedoman Penyelenggaraan Pendidikan UPI 20141 (pp. 1-100). http://www3.upi.edu/main/file/akademik/e a9ce-pedoman-penyelenggaraanpendidikan-upi-tahun-2019.pdf

UU No 12/2012. (2012). UU No 12 Tahun 2012 Tentang Pendidikan Tinggi. Republik Indonesia, 12. 